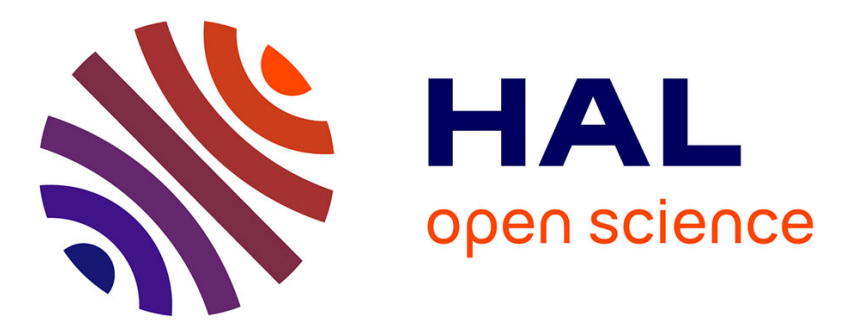

\title{
Novel approach to fast determination of 64 pesticides using of ultra-performance liquid chromatography-tandem mass spectrometry (UPLC-MS/MS)
}

Tomas Kovalczuk, Ondrej Lacina, Martin Jech, Jan Poustka, Jana Hajslova

\section{To cite this version:}

Tomas Kovalczuk, Ondrej Lacina, Martin Jech, Jan Poustka, Jana Hajslova. Novel approach to fast determination of 64 pesticides using of ultra-performance liquid chromatography-tandem mass spectrometry (UPLC-MS/MS). Food Additives and Contaminants, 2008, 25 (04), pp.444-457. 10.1080/02652030701570156 . hal-00577414

\author{
HAL Id: hal-00577414 \\ https://hal.science/hal-00577414
}

Submitted on 17 Mar 2011

HAL is a multi-disciplinary open access archive for the deposit and dissemination of scientific research documents, whether they are published or not. The documents may come from teaching and research institutions in France or abroad, or from public or private research centers.
L'archive ouverte pluridisciplinaire HAL, est destinée au dépôt et à la diffusion de documents scientifiques de niveau recherche, publiés ou non, émanant des établissements d'enseignement et de recherche français ou étrangers, des laboratoires publics ou privés. 


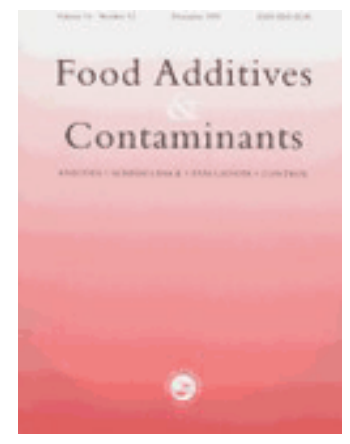

\section{Novel approach to fast determination of 64 pesticides using of ultra-performance liquid chromatography-tandem mass spectrometry (UPLC-MS/MS)}

\begin{tabular}{|c|c|}
\hline Journal: & Food Additives and Contaminants \\
\hline Manuscript ID: & TFAC-2007-065.R1 \\
\hline Manuscript Type: & Original Research Paper \\
\hline $\begin{array}{r}\text { Date Submitted by the } \\
\text { Author: }\end{array}$ & 07-Jul-2007 \\
\hline Complete List of Authors: & $\begin{array}{l}\text { Kovalczuk, Tomas; Institute of Chemical Technology Prague, } \\
\text { Department of Food Chemistry and Analysis } \\
\text { Lacina, Ondrej; Institute of Chemical Technology Prague, } \\
\text { Department of Food Chemistry and Analysis } \\
\text { Jech, Martin; Institute of Chemical Technology Prague, Department } \\
\text { of Food Chemistry and Analysis } \\
\text { Poustka, Jan; Institute of Chemical Technology Prague, Department } \\
\text { of Food Chemistry and Analysis } \\
\text { Hajslova, Jana; Institute of Chemical Technology Prague, } \\
\text { Department of Food Chemistry and Analysis }\end{array}$ \\
\hline Methods/Techniques: & Chromatography - UPLC-MS/MS, QuEChERS Clean-up \\
\hline Additives/Contaminants: & Pesticide residues \\
\hline Food Types: & Baby food, Fruit \\
\hline
\end{tabular}

\section{SCHOLARONE \\ Manuscripts}




\title{
Novel approach to fast determination of pesticides using of ultra- performance liquid chromatography - tandem mass spectrometry (UPLC- MS/MS)
}

Tomáš Kovalczuk, Ondřej Lacina, Martin Jech, Jan Poustka and Jana Hajšlová*,

Institute of Chemical Technology, Dept. of Food Chemistry and Analysis, Technická 3, 166 28 Prague 6, Czech Republic

* Corresponding author

E-mail: jana.hajslova@vscht.cz

\begin{abstract}
Rapid, high throughput method employing ultra-performance liquid chromatography hyphenated with tandem quadrupole mass spectrometry (UPLC-MS/MS) has been developed and optimized for simultaneous quantification and confirmation of 64 pesticide residues and their toxic metabolites in fruit extracts prepared by buffered QuEChERS procedure. Total time required for UPLC-MS/MS analysis was $8 \mathrm{~min}$ plus $2 \mathrm{~min}$ for re-equilibration to initial UPLC conditions. Performance characteristics were determined for apple extracts spiked at $10 \mu \mathrm{g} \mathrm{kg}^{-1}$. Repeatability of measurements expressed as relative standard deviations was in the range $1.5-13 \%$ at this level for most analytes. Thanks to very low limits of quantification ( $<10 \mu \mathrm{g} \mathrm{kg}^{-1}$ for majority of pesticides), optimized method allows reliable control of not only common MRLs set in EU regulation for various pesticides/fruit combinations but also uniform MRL $10 \mu \mathrm{g} \mathrm{kg}^{-1}$ endorsed for baby food.
\end{abstract}




\section{Introduction}

Pesticides applied at various stages of food crops cultivation and/or during their post-harvest storage, play an important role in intensification of agricultural production. The number of active ingredients intended for control of undesirable pests and weeds currently exceeds 800 (Tomlin 2002, Fernández-Alba 2005, Hertherton et al. 2004). Avoiding occurrence of some pesticide residues in food supply is obviously impossible to achieve and, therefore, not surprisingly, health risk associated with a dietary intake of these chemicals has become a safety issue, both for toxicologists and consumers. To address these concerns, reliable and cost effective analytical methods have to be available to control respective regulation requirements.

With regard to the high number of target analytes concerned, multiresidue methods represent the only practical solution that enables meeting the requirements of current extensive surveillance/compliance programs, both in terms of scope of analysis and the number of samples analyzed. Historically, gas chromatography (GC) used to be the main technique employed for this purpose. As documented in recent reviews (Hertherton et al. 2004, Hernández et al. 2006), GC-based multiresidue methods are still widely used in control laboratories worldwide, nevertheless, it should be noted that their scope becomes more and more insufficient. Many registered pesticides are relatively polar compounds, not amenable to direct GC analysis, and on this account, development/validation of a broad-scope procedures employing high-performance liquid chromatography (HPLC) for sample separation and selective detection strategy, such as tandem mass spectrometry (MS/MS), has become an urgent task.

Most of published LC-MS based methods involve either extensive, cost and labour demanding clean-up procedures for processing of crude extracts, what, unavoidably, results in a loss of some target analytes. Similarly, solvent-exchange step, which is in some cases carried out prior to introduction of extract onto LC column, makes the sample preparation process less effective (Hertherton et al. 2004). Challenges exists both in innovation of sample handling strategies and use of novel instrumentation applicable for determinative step. Regarding the first aspect, significant increase of sample throughput, reduction of labour demands and improvement of cost-effectiveness can be obviously achieved by implementation of so called QuEChERS method (Quick, Easy, Cheap, Effective, Rugged, Safe) originally developed for GC-based analysis of multiple pesticide residues in 
fruits/vegetables (Anastassiades et al. 2003). Acetonitrile extraction accompanied by simultaneous liquid-liquid partitioning is followed by dispersive SPE clean-up. According to recently modified version, either acetonitrile containing $1 \%$ acetic acid and acetate buffer (Lehotay et al. a. 2005) or citrate buffer (www.quechers.com) are used in the first step. Regarding the measurement tools, current LC-MS/MS instruments enable, thanks to novel designs of ion sources and availability of fast electronics, determination of large range of pesticides in complex matrices at (ultra)trace levels and, in addition, also an on-line confirmation of residues identity (Hertherton et al. 2004, Leandro et al. 2006, Soler et al. 2006). In older studies there was a tendency to develop LC-MS method only for a single residue or small multiresidue set of chemically related pesticides that were not amenable to GC analysis because of their high polarity or low thermal stability (e.g. Fernández at al. 2006). Some of until now published LC-MS/MS-based methods (Hertherton et al. 2004, Hernández et al. 2006, Lehotay et al. b. 2005, Hancock et al. 2004, Janson et al. 2004, Klein et al. 2003, Alder et al. 2004, Ortelli et al. 2004) enable control of more than 50 pesticides in one chromatographic run, however, only one of them (Hertherton et al. 2004) allows simultaneous acquisition of two MS/MS transitions for all analytes in the method. It should be noted that only one MS/MS transition monitored for each analyte does not provide absolute confirmation of identity and further evidence may be required, especially in cases when particular MRL is exceeded (Commission document No. SANCO/10232/2006).

In general terms, several confirmative strategies could be employed. However, some of them, such as a change of LC separation system intended for confirmation based on retention times conformity and/or switching to a MS ionization mode employing different principle (e.g. ESI vs. APCI) are not convenient or feasible from practical point of view. Medium and/or high resolution MS detectors (Commission document SANCO/10232/2006), e.g. those employing time-of-flight (TOF) mass analyzers, represent another alternative for detection of target analytes. It should be noted, however, that only hybrid instruments, such as quadrupole-timeof-flight (Q-TOF), allow full confirmation of particular analyte. Currently, most laboratories specialized in pesticide residue analysis prefer affordable low resolution MS/MS for analysis of target compounds, as an optimal option enabling both quantification and confirmation of target pesticides at trace levels (Hertherton et al. 2004, Hernández et al. 2006, Anastassiades et al. 2003, Lehotay et al. a,b 2005, Fernández et al. 2000, Hancock et al. 2004, Janson et al. 2004, Klein et al. 2003, Alder et al. 2004, Ortelli et al. 2004, Leandro et al. 2006, Kovalczuk et al. 2006, Mezcua at al. 2006, Díez et al. 2006, Zrostlíková et al. 2003). To correctly 
confirm detected pesticides minimally two specific MS/MS transitions monitored for each analyte are then required (Soler et al. 2006, Leandro et al. 2006, Hertherton et al. 2004).

Regarding instrumental set-up, most of current LC-MS/MS based multiresidue methods employ conventional HPLC systems for separation of sample components. (Hertherton et al. 2004, Hernández et al. 2006, Lehotay et al. b. 2005, Hancock et al. 2004, Janson et al. 2004, Klein et al. 2003, Alder et al. 2004, Ortelli et al. 2004, Soler 2006). The sufficient separation of multiple residues (tens, even hundreds of analytes) in HPLC-MS/MS methods can be accomplished as soon as within 20-30 min, however, the need to carry out post run column reequilibration may increase the total analysis time up to 30-40 min. On this account, instrumental analysis becomes a limiting step in laboratory throughput. In theory, there are also other strategies that can increase the speed of chromatographic separation such as increase of mobile phase flow rate or the use of shorter columns (Kovalczuk et al. 2006), however none of them is suitable for trace analysis of multiple pesticide residues in complex matrices such as food. The recent introduction of ultra-performance liquid chromatography (UPLC) system, such as Acquity ${ }^{\mathrm{TM}}$, is capable to operate conventional "HPLC size" columns with small $(1.7 \mu \mathrm{m})$ porous particles at pressures as high as $15000 \mathrm{psi}(1025 \mathrm{bar})$ has offered a new challenge to increase significantly number of analyzed samples per day. Under these conditions, the van Deemter equation indicates that a significant gain in efficiency is not diminished at increased flow rates of mobile phase. (Leandro et al. 2006). As demonstrated in recently published studies (Leandro et al. 2006, Kovalczuk et al. 2006), the improvement of several methods performance parameters including decrease of limits of detection (LODs) and other characteristics depends on particular experimental set-up.

The aim of presented study was to develop a fast multiresidue UPLC-MS/MS method with performance characteristics fully complying with EU legislation requirements (Commission document No SANCO/10232/2006), both for common fruit commodities and fruit-based baby food. The potential of Acquity UPLC system (Waters) hyphenated with Quattro Premier XE tandem quadrupole mass spectrometer (Waters) was demonstrated in determination of multiple pesticide residues in apple extract prepared by QuEChERS procedure.

\section{Experimental}

\section{Chemicals and material}

Certified pesticide standards obtained from Dr. Ehrenstorfer GmbH (Germany) and/or Riedel de Haen (Germany) were used for preparation of individual stock standard solutions 
(concentrations in the range $0.3-3 \mathrm{mg} \mathrm{mL}^{-1}$ ) in either methanol, acetonitrile or acetone:acetonitrile mixture $(1: 9, \mathrm{v} / \mathrm{v})$ depending on the solubility of particular pesticide. These solutions were used for preparation of: (i) individual stock standard solutions in methanol (1-5 $\left.\mu \mathrm{g} \mathrm{mL}^{-1}\right)$ for electrospray (ESI) source tuning and MS/MS transitions settings and (ii) preparation of mixed standard solution in acetonitrile $\left(1 \mu \mathrm{g} \mathrm{mL} L^{-1}\right)$. The working standard solutions $\left(0.25-5000 \mathrm{ng} \mathrm{mL}^{-1}\right)$ used for calibration were then prepared from this solution by dilution with acetonitrile.

Deionised water for preparation of a mobile phase was produced by Milli-Q apparatus (Millipore, Germany). Ammonium acetate $99.99 \%$ was obtained from Sigma-Aldrich (Germany), acetonitrile (Sigma-Aldrich, Germany) and methanol (Merck, Germany) were HPLC gradient grade solvents for pesticide residue analysis. The glacial acetic acid 99.99+ was purchased from Sigma-Aldrich (Germany). Anhydrous magnesium sulfate, sodium acetate trihydrate and acetone were obtained from Penta (Czech Republic), and BondesilPrimary-secondary amine (PSA, $40 \mu \mathrm{m}$ ) sorbent was purchased from Varian (USA). The magnesium sulfate was heated for $8 \mathrm{~h}$ at $520^{\circ} \mathrm{C}$ in a muffle furnace to remove any residual water. Apple samples free of pesticide residues were obtained from an ecological farm. Apple-based baby food was obtained from retail market.

\section{Sample preparation}

The buffered QuEChERS procedure was employed within the pre-analytical step. Blank apples (obtained from organic farm) were used for preparation of blank extracts. Representative apple sample $(3 \mathrm{~kg}$ ) was thoroughly homogenized using 2094 Homogenizer (Foss Tecator, Sweden). $10 \mathrm{~g}$ of homogenate were weighted into PTFE centrifugation tube $(50 \mathrm{~mL})$ and shaken vigorously for $1 \mathrm{~min}$ with $1 \%(\mathrm{v} / \mathrm{v})$ acetic acid in acetonitrile. Anhydrous magnesium sulfate $(4 \mathrm{~g})$ and sodium acetate trihydrate $(1.6 \mathrm{~g})$ were added and the sample was then immediately vortexed (Ika-Werke, Germany) to prevent formation of coagulated magnesium sulfate. After shaking for $30 \mathrm{~s}$, the samples were centrifuged (Hettich, Germany) at $11000 \mathrm{RPM}$ for $5 \mathrm{~min} .2 \mathrm{~mL}$ of supernatant were transferred into another PTFE tube (14 $\mathrm{mL})$ containing anhydrous magnesium sulfate $(300 \mathrm{mg})$ and primary-secondary amine (PSA) sorbent $(100 \mathrm{mg})$. After shaking by Vortex and centrifugation (11 000 RPM, $5 \mathrm{~min})$, the supernatant was filtered through $0.2 \mu \mathrm{m}$ PTFE filter (National Scientific, USA). All purified blank extracts were combined. $950 \mu \mathrm{L}$ of this extract were then mixed with $50 \mu \mathrm{L}$ of appropriate mixed working standard solution in acetonitrile and aliquot $(5 \mu \mathrm{L})$ of this spiked 
extract was then analyzed by UPLC-MS/MS. The step following UPLC-MS/MS method optimization was its application to apple-based baby food analysis.

\section{UPLC-MS/MS Analysis}

UPLC analyses were performed using an Acquity ${ }^{\mathrm{TM}}$ UPLC system (Waters, USA) equipped with Acquity ${ }^{\mathrm{TM}}$ UPLC BEH $\mathrm{C}_{18}$ separation column $(100$ x $2.1 \mathrm{~mm}, 1.7 \mu \mathrm{m})$ (Waters, USA). The sample temperature as well as column temperature was maintained at $25^{\circ} \mathrm{C}$. The mobile phase contained $0.005 \mathrm{M}$ ammonium acetate in deionised water (A) and methanol (B), the flow rate was $0.3 \mathrm{~mL} \mathrm{~min}^{-1}$.

For UPLC separation the gradient elution was employed, starting composition of $20 \% \mathrm{~B}$, rising linearly to $100 \% \mathrm{~B}$ over $6 \mathrm{~min}$, and then held for $2 \mathrm{~min}$ at $100 \% \mathrm{~B}$. $2 \mathrm{~min}$ reequilibration to initial mobile phase composition followed. Sample injection volume $5 \mu \mathrm{L}$ was used in all experiments.

Identification/quantitation of target analytes was performed using the Quattro Premier XE tandem mass spectrometer (Waters, USA). The detector was operated in a positive electrospray (ESI+) ionization mode. Multiple reaction monitoring (MRM) conditions (collision energy and cone voltage) were optimized for each pesticide during infusion (5 $\mu \mathrm{L}$ $\min ^{-1}$ ) of individual pesticide solution $\left(1-5 \mu \mathrm{g} \mathrm{mL}^{-1}\right.$ ) into the mobile phase flow (A:B 50:50,

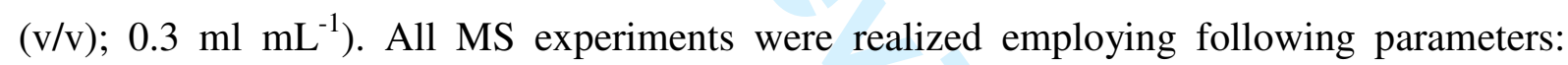
capillary voltage $3.5 \mathrm{kV}$, extractor voltage $4 \mathrm{~V}$, source temperature $120^{\circ} \mathrm{C}$, desolvation temperature $250^{\circ} \mathrm{C}$, cone gas flow $100 \mathrm{~L} \mathrm{~h}^{-1}$ and desolvation gas flow $700 \mathrm{~L} \mathrm{~h}^{-1}$ (both gases were nitrogen). Argon was used as a collision gas $\left(3.310^{-3} \mathrm{mbar}\right)$. Tuned and optimized MS/MS transitions as well as specific cone voltages and collision energies are summarized in Table 1. Analytes were divided into MRM segments based on their elution characteristics (Table 1). In each of these segments selected MS/MS transitions were monitored at the same dwell time $5 \mathrm{~ms}$, inter-channel and inter-scan delays of $10 \mathrm{~ms}$ for all transitions. Generated experimental data were processed using MassLynx software version 4.0 Service Pack 4, Software Change Note \#462 (Waters, USA).

[Insert Table 1 about here]

\section{Method performance}

The analytes mixture in pure solvent was repeatedly analyzed within the optimization/development of UPLC-MS/MS to tune chromatographic and MS/MS parameters. Repeatability and LODs of UPLC-MS/MS method were obtained on the basis of 
data generated through six replicate sequences comprising set of matrix-matched standards consisting of 10 purified apple extracts spiked by target analytes mixture at levels: 250; 150; $50 ; 20 ; 10 ; 5 ; 2 ; 1 ; 0.5$ and $0.25 \mu \mathrm{g} \mathrm{kg}^{-1}$, respectively. Prior to running the sequences, the eletrospray (ESI) source chamber was cleaned and then twelve repeated injections of blank sample extract were performed to minimize the changes of analytes responses within the initial injections of test samples. The LOD for each pesticide was estimated as an analyte concentration, at which signal to noise ratio value for primary MS/MS at least 3 ( $\mathrm{S} / \mathrm{N} \geq 3$ ) was obtained within all six sequences (described above). For S/N estimation Peak-to-peak (PtP) strategy integrated in the MassLynx software was employed. The limit of quantitation (LOQ), (fixed as lowest calibration level - LCL) was defined as an analyte concentration at which following requirements were met: (i) primary MS/MS transition - $\mathrm{S} / \mathrm{N} \geq 5$ and (ii) secondary MS/MS transition - S/N $\geq 3$ obtained in all six sequences. Within the study also the matrix effect for each analyte was estimated. The calculation resulted from replicated analyses of six sequences comprising: (i) set of spiked purified apple extracts $\mathrm{M}_{1}-\mathrm{M}_{3}$ (prepared as described in chapter 3.3) at levels 10,20 and $50 \mu \mathrm{g} \mathrm{kg}^{-1}$ (ii) standards in pure solvent $\left(\mathrm{S}_{1}-\mathrm{S}_{3}\right)$ at levels: 10, 20 and $50 \mathrm{ng} \mathrm{mL}^{-1}$ (prepared as described in section "Chemicals and material") and (iii) blank apple extracts (B); (prepared as described in section "Sample preparation"). The injection order within the sequence for ME investigation is shown in Table 2. The blank apple extract was analyzed to check the cross-contamination within the sample injections. The value of matrix effect was calculated as a ratio of average area of matrix-matched standards and average area of solvent standards for each analyte.

[Insert Table 2 about here]

\section{Results and discussion}

\section{Sample preparation}

Depending on a sample preparation strategy, various co-extracts are contained in analyzed samples (Díez et al. 2006, Hercegová et al. 2004, Zrostlíková et al. 2003, Alder et al.2004). Their amount and character may influence, in a different extent, the overall performance of respective analytical method. From a wide range of isolation/purification approaches conceivable in pesticide residue analysis (e.g. described by Fernández-Alba 2005, Lehotay et al. a. 2005, Janson et al. 2004, Leandro et al. 2006) recently introduced QuEChERS strategy (Anastassiades et al. 2003, Lehotay et al. b. 2005) was chosen for our study. As demonstrated 
within international collaborative studies (Lehotay at al. a. 2005, Díez et al. 2006) for low fat matrices such as fruits/vegetables, QuEChERS currently represents the most challenging preanalytical option for analysis of a wide range of pesticides representing various polarity classes. Based on the list of target analytes involved in these studies, representatives of various pesticide classes were selected for our experiments. Another option we had to decide was the choice of optimal solvent strength for introduction of QuEChERS extract (acetonitrile solution) onto UPLC column. Theoretically, dilution of sample by water should be carried out to obtain a solvent strength similar to initial mobile phase composition (in particular case A:B $8: 2, \mathrm{v} / \mathrm{v})$. Such approach was employed in most of LC-MS based studies employing various "classic" sample preparation techniques (e.g. Hertherton 2004, Hernández et al. 2006, Hancock at al. 2004, Klein and Alder 2003, Alder et al. 2004). However, addition of water to QuEChERS acetonitrile extract may result in the matrix precipitation and, consequently, in some loss of target analytes. With regards to these problems, undiluted sample was injected. Thanks to its low volume $(5 \mu \mathrm{l})$, a distortion of early eluting peaks was negligible. Although some sensitivity was sacrificed by reduction of sample equivalent to $5 \mathrm{mg}$, the LODs were still low enough, to enable reliable control of "baby food limit" $\left(10 \mu \mathrm{g} \mathrm{kg}^{-1}\right)$ for most of analytes. Moreover, decreasing of sample load also increases column life-time and reduces the demands for MS source maintenance.

\section{UPLC-MS/MS}

\section{MS/MS parameters}

With regards to the principles of confirmation defined in recent Commission document No. SANCO/10232/2006, overwhelming evidence that sample actually contains particular pesticide, i.e. proof of its identity, has to be provided by respective analytical procedure. To meet this requirement and avoid the need of positive samples re-analysis, we aimed to incorporate two MS/MS transitions to get a required specificity of detection process for all analytes. Contrary to the majority of existing multiresidue LC-MS/MS methods in which (as a compromise enabling to achieve low enough LODs for a wide range of analytes) only one MS/MS transitions was monitored, two selective transitions with the highest abundance were selected for detection in our study. The confirmation of identity was based on the ion ratio statistics for two MS/MS transitions monitored, as recommended by Commission document No. SANCO/10232/2006 and as usually applied in the analysis of veterinary drugs residues (Commission Decision of 12 August 2002 implementing Council Directive 96/23/EC 
concerning the performance of analytical methods and the interpretation of results (2002/657/EC). This strategy has been demonstrated as suitable for analysis of residues in plant materials by other authors (Leandro et al. 2006, Hertherton et al. 2004, Soler 2006). Analytes detection and fragmentation parameters (cone voltages and collision energies) were optimized, under ESI+ conditions by infusing a standard solution by a syringe pump into the mobile phase. Alike in similar studies (Hertherton et al. 2004, Hernández et al. 2006, Leandro et al. 2006), maximum permitted tolerances for relative ion ratios (Commission document SANCO/10232/2006) were considered for confirmation in presented procedure employing MRM mode. Phorate was only pesticide for which secondary (qualifying) MS/MS transition was not established. Confirmation of this compound, based on ion ratio, was therefore impossible.

\section{MRM optimization}

In theory, the replacement of conventional HPLC column (particles in the range 3-5 $\mu \mathrm{m}$ ) with novel UPLC columns with sorbent consisting of small particles $(2 \mu \mathrm{m}$ and less) results in reduced heights of theoretical plate (HETP) and increased peak capacity (Leandro et al. 2006, Kovalczuk et al. 2006). As far as narrow peaks such as those generated in UPLC analysis are to be accurately integrated, MS scanning frequency has to be adjusted properly. For meeting the sufficient data density, i.e. at least 10 data points (Hill et al. 2002) across the peak ,even for analytes at the lowest calibration levels, the dwell time period was set down to $5 \mathrm{~ms}$, what is a minimal setting attainable by Quattro Premier XE instrument, inter-scan and inter-channel delays were then $10 \mathrm{~ms}$ (under this setting the density for peaks at $150 \mu \mathrm{g} \mathrm{kg}^{-1}$ was rather excessive, 20-30). With regard to high number of analytes eluted within a short time, and considering strong requirement for low LODs in pesticide residue analysis, several time windows, within which only a limited number of MS/MS transitions is monitored, have to be established across the chromatogram. Unfortunately, under real-life conditions, slight fluctuation of analytes retention times may occur, namely during analysis of large series of samples. Therefore, to avoid running of analytes out of their elution slot, some overlap of these time windows has to be established for reliable acquisition of respective data. Increased number of MS/MS transitions is then monitored in the area of overlap and, consequently, acquisition frequency may significantly decrease. As far as acquisition of data points for particular analyte occurs under largely differing scanning speeds, as shown for aldicarb in Fig. 1A, poor repeatability of generated data (relative standard deviation (RSD) $23 \%$ in particular case) is typically encountered. 
[Insert Figure 1 about here]

One of conceivable strategies to minimize the above unfavourable effects is illustrated in Fig. 1B. In this case, some peaks in chromatogram are eluted within the overlap of adjacent windows, in which, both the scanning speed and dwell time are equal or very similar. Repeatability of areas of peaks eluted at the segment "borderline" is fairly improved due to only small differences in acquisition set-up across the analyte elution band. Using this approach repeatability of aldicarb measurement (expressed as RSD) was as low as 6\%. It should be noted, however, that optimization of windows setting is a very demanding task and any the expanding method scope (adding of a new analyte), is rather complicated.

In Fig. 1C, further improved, obviously simpler approach is presented. Contrary to the previous strategy, elimination of problems associated with the overlap of time windows characterized by different scanning conditions is achieved by separating analytes into many time segments within witch only a small number of MS/MS transitions is monitored. This setup allows a large flexibility in the method optimization, since modification of windows overlap (when needed), does not result in significant changes in scanning frequencies. In addition, for some peaks a special MRM segment including respective two characteristics MS/MS transitions can be easily added without a significant change of the scanning frequency. Example in Fig. 1C shows flexible settings of "tailor-made" windows for aldicarb. The later strategy was employed in comprehensive optimization of the current UPLC-MS/MS procedure.

\section{Method performance characteristics}

Considering a large number of registered pesticide/fruit combinations involved in various surveillance/compliance studies, it was obviously impossible to carry out the validation of UPLC-MS/MS procedure for all of them. On this account, generic approach was adopted for set-up of this study. The choice of test matrice was based on assumptions on comparable nature of matrix effects occurring in LC-MS/MS analysis of commodities characterized by similar composition (Commission document No. SANCO/10232/2006, Hercegová et al. 2004), i.e. similar nature of co-extracts interfering with ionization process. In particular case, apples were selected for our study as a representative of high moisture low fat commodity category. The applicability of a new method in the final phase of study was demonstrated on analyses of apple-based fruit baby foods. 
For most of residues, optimized method allowed to obtain LODs and LOQs (lower than 10 $\mu \mathrm{g} \mathrm{kg}^{-1}$, see Table 3) what enables to use it also for control of uniform baby food MRL set at this level. For two "priority" pesticides specified in EU Commission Directive 2003/13/EC included into our study (oxydemethon methyl and demethon-S-methyl sulfone) LODs 0.5 $\mu \mathrm{g} \mathrm{kg}^{-1}$ were obtained, what allows their reliable control of even lower level. (MRL for demethon-S-methyl is $6 \mu \mathrm{g} \mathrm{kg}^{-1}$, expressed as sum of demethon-S-methyl, oxydemethonmethyl and demethon -S-methyl sulfone). The calibration curves were realized by six calibration sets of spiked QuEChERS apple extracts over a wide concentration range 0.25-250 $\mathrm{ng} \mathrm{mL} \mathrm{m}^{-1}$ (equivalent to contamination level $0.25-250 \mu \mathrm{g} \mathrm{kg}^{-1}$, prepared as described in 3.4). The correlation coefficient $\left(\mathrm{R}^{2}\right)$ was calculated by MassLynx software for the concentration range LOQ-250 $\mathrm{g} \mathrm{kg}^{-1}$, (corresponds to LOQ-250 $\mathrm{ng} \mathrm{mL} \mathrm{m}^{-1}$ ). For the majority of tested pesticides the calibration curves were linear (correlation coefficient $R^{2}>0.98$ ) over the tested range. As shown in Table 3, for acetamiprid, carbendazim, carbofuran, pirimicarb and thiacloprid, excellent linearity was achieved over the whole calibration range $\left(0.25-250 \mu \mathrm{g} \mathrm{kg}^{-}\right.$ $1)$.

It should be noted that the applicability of QuEChERS pre-analytical procedure for isolation of a wide range of pesticides from apples and similar matrices was reported in earlier published studies (Anastassiades et al. 2003, Lehotay et al. a,b 2005, Díez et al. 2006) and, therefore, recoveries of target analytes were not examined in our experiments. The current study was mainly focused on critical assessment of performance characteristics of UPLCMS/MS determinative step, and on this account, only spiked extracts prepared from blank apples were analyzed. Regarding random errors of six repeated injections (as described in 3.4), relatively low RSDs $6 \%$ in average were found for all the tested pesticides at concentration level $10 \mu \mathrm{g} \mathrm{kg}^{-1}$. For only few analytes with $\mathrm{LOQ}>10 \mu \mathrm{g} \mathrm{kg}^{-1}$ the repeatability was calculated at their LOQ (see Table 3). Dodine was the only pesticide for which the RSD exceeded 20\% (see Table 3). The uncertainty of measurement of this troublesome analyte (see Fig. 2), as documented in our long-term records, increases with growing number of samples analyzed on Acquity BEH C18 separation column. Although column with different stationary phase (Discovery $\mathrm{C}_{18}$ ) was used in our routine multiresidue HPLC-MS/MS method, similar problems were encountered.

[Insert Table 3 about here], [Insert Figure 2 about here] 
The suppression/enhancement of individual analytes signal measured in the presence of matrix components, i.e. matrix effect, was estimated on the basis of comparison with pure solvent standard. Within this study, matrix effects ranging from 55 to $160 \%$ were observed, with the highest enhancement of response obtained for azoxystrobin, and the most intensive signal suppression found for spiroxamine. Although for most of analytes matrix effects were in acceptable range 80-120\%, the matrix-matched standards were used for quantification thorough the study to achieve good accuracy of generated data.

The possibility to obtain significant reduction of analysis time by the use of UPLC-MS/MS system, even in case of such complex sample as multiple residues in plant matrices, was documented. The UPLC-MS/MS examination of apple extract was completed within $8 \mathrm{~min}$ (see Fig. 3). Compared to similar procedures employing conventional HPLC-MS/MS systems sample throughput was approx. 3-4 times higher, as summarized in Fig. 4.

The time necessary for re-equilibration the separation column was set to $2 \mathrm{~min}$, and as documented by negligible RSDs of retention times $(0.11-0.36 \%)$, this time was sufficient enough for their good repeatability.

[Insert Figure 3 and 4 about here]

\section{Conclusions}

The UPLC Acquity separation system (Waters) coupled with Premier Quattro XE (Waters) tandem quadrupole mass spectrometric detector, used for analysis of multiple pesticide residues, enabled an overall improvement of method performance characteristics when QUEChERS apple extract was injected:

- Due to the reduced band broadening on a high resolution UPLC column, narrower analyte peaks, hence increased signal to noise ratios, were obtained. This resulted in achieving limits of quantification (LOQs) for most pesticides fairly below $10 \mu \mathrm{g} \mathrm{kg}^{-1}$. Under these conditions, not only MRLs established by EU regulation for common fruit commodities, but also uniform baby food limit $\left(10 \mu \mathrm{g} \mathrm{kg}^{-1}\right)$ can be reliably controlled.

- Thanks to the high detection sensitivity, simultaneous acquisition of two characteristic MS/MS transitions was possible for all the target analytes. In this way, contrary to most of currently existing LC-MS based methods, on-line confirmation of residues 


\section{Acknowledgement}

This study was a part of research project MSM 6046137505 granted by Ministry of Education, Youth and Sports of the Czech Republic. UPLC system Acquity loan, before its purchase is acknowledged to WATERS Gesellschaft m.b.H, Prague, Czech Republic.

\section{References}

Alder L., Luderlitz S., Lindtner K., Stan H-J. 2004. The ECHO technique - the more effective way of data evaluation in liquid chromatography-tandem mass spectrometry analysis. Journal of Chromatography A 1058: 67-79

Anastassiades M., Lehotay S.J., Štajbaher D., Schenck F. 2003. Fast and easy multiresidue method employing acetonitrile extraction/partitioning and "dispersive solid-phase 
extraction" for the determination of pesticide residues in produce. Journal of AOAC International 86: 412-431

Commission Directive 2003/13/EC of 10 February 2003 amending Directive 96/25/EC on processed cereal-based foods and baby foods for infants and young children, Official Journal L41/33

Díez C., Traag W.A., Zommer P., Marinero P., Atienza J. 2006. Comparison of an acetonitrile extraction/partitioning and "dispersive solid-phase extraction" method with classical multi-residue methods for the extraction of herbicide residues in barley samples. Journal of Chromatography A 1131:11-23

European Commission, directorate General Health and Consumer Protection, Commission document SANCO/10232/2006, Quality Control Procedures for Pesticide Residue $\begin{array}{llll}\text { Analysis, } & 2006 . & \text { Available }\end{array}$ http://ec.europa.eu/food/plant/protection/resources/qualcontrol_en.pdf. Accessed 2007 February 20.

Fernández M., Picó Y., Manes J. 2000. Determination of carbamate residues in fruits and vegetables by matrix solid-phase dispersion and liquid chromatography-mass spectrometry. Journal of Chromatography A 871;43-56

Fernández-Alba A.R. (ed) 2005. Vol. XLIII - Chromatographic-Mass Spectrometric Food Analysis for Trace Determination of Pesticide Residue. In: Comprehensive Analytical Chemistry $s$, Elsevier, Amsterdam

Hancock P., Kearney G., Newton A., Alder L., Klein J. 2004. An enhanced LC/MS/MS method for the determination of 81 pesticide residues in fruit and vegetables using the Quattro Premier Mass Spectrometer. Waters Corporation (USA) Application Note Database [Internet]. 2004 - [cited 2007 Feb 20]. Available from: http://www.waters.com/WATERSDIVISION/pdfs/720000840EN.pdf

Hercegová A.,Dömötörová M, Matisová E, Kirchner M., Otrekal R., Štefuca V. 2005. Fast gas chromatography with solid phase extraction clean-up for ultratrace analysis of pesticide residues in baby food. Journal of Chromatography A 1084: 46-53.

Hernández F, Pozo O.J., Sanco J.V., Biljsma L., Barreda M., Pitarch E. 2006. Multiresidue liquid chromatography tandem mass spectrometry determination of 52 non gas chromatography-amenable pesticides and metabolites in different food commodities. Journal of Chromatography A 1109: 242-252 
Hertherton C.L., Sykes, M.D., Fussell R.J., Goodall D.M. 2004. A multi-residue screening method for the determination of 73 pesticides and metabolites in fruit and vegetables using high-performance liquid chromatography/tandem mass spectrometry. Rapid Communications in Mass Spectrometry 18: 2443-2450

Hill H.M., Smeraglia J, Brodie R.R., Smith G.T, 2OO4. Where do you need draw the line? Points consider when Implementing the FDA Method Validation Guidance on Qualifying Chromatographic Peaks, Chromatographia Suppl. 55: S-79-S-81

http://www.quechers.com [internet]. Accessed 2007 Feb 20.

Janson C., Pihlström T., Österdahl B., Markides K.E. 2004. A new multi-residue method for analysis of pesticide residues in fruit and vegetables using liquid chromatography with tandem mass spectrometric detection. Journal of Chromatography A 1023: 93-104

Klein J, Alder L. 2003. Applicability of gradient liquid chromatography with tandem mass spectrometry to simultaneous screening for about 100 pesticides in crops. Journal of AOAC International 86: 1015-1037

Kovalczuk T., Jech M., Poustka J, Hajšlová J. 2006. Ultra-performance liquid chromatography-tandem mass spectrometry: A novel challenge in multiresidue pesticide analysis in food. Analytica Chimica Acta 577:8

Leandro C.C, Hancock P, Fussell, R.J., Keely B.J. 2006. Comparison of ultra-performance liquid chromatography and high-performance liquid chromatography for the determination of priority pesticides in baby foods by tandem quadrupole mass spectrometry. Journal of Chromatography A, 1103: 94-101.

Lehotay S. (a) de Kok A., Hiemstra M., van Bodegraven P. 2005. Validation of fast and easy method for the determination of residues from 229 pesticides in fruits and vegetables using gas and liquid chromatography and mass spectrometry. Journal of AOAC International 88: 595-614

Lehotay S. (b), Maštovská K., Lightfield A. 2005. Use of buffering and other means to improve results of problematic pesticides in a fast and easy method for residue analysis of fruits and vegetables. Journal of AOAC International 88: 615-629

Mezcua M., Agüera A., Lliberia J.L., Cortés M.A, Bagó B., Fernández-Alba. 2006. Application of ultra performance liquid chromatography-tandem mass spectrometry to the analysis of priority pesticides in groundwater . Journal of Chromatography A 1109:222-227 
Orteli D., Edder P., Corvi C. 2004. Multiresidue analysis of 74 pesticides in fruits and vegetables by liquid chromatography-electrospray-tandem mass spectrometry. Analytica Chimica Acta 520: 33-45

Soler C., Hamilton B., Furey A., James K.J., Mañes J., Pocó Y. 2006, Optimization of LCMS/MS using triple quadrupole mass analyzer for simultaneousnanalysis of carbosulfan and its main metabilites in oranges. Analytica Chimica Acta 571: 1-11

Tomlin C.D.S. (ed) 2002. In: The e-Pesticide Manual, BCPC, $\left(12^{\text {th }}\right.$ edn). Version 2.2., 20022003

Zrostlíková J., Hajšlová J., Kovalczuk T., Štěpán R., Poustka J. 2003. Determination of seventeen polar/thermolabile pesticides in apples and apricots by liquid chromatography mass spectrometry. Journal of AOAC International 86: 612-622 
Figure 1: The impact of data acquisition setting in UPLC-MS/MS (changes of scanning frequency) on recording of analyte elution profile; aldicarb was shown as an example: In each segment a certain number of MS/MS transitions was monitored according to particular MRM method. The total number of MS/MS transitions monitored in each moment, expressed as the sum of all overlapped segments is shown below each chromatogram. The phenomenon of poor repeatability based on largely changed scanning frequencies is demonstrated on peak of aldicarb. For details see paragraph "MRM optimization".

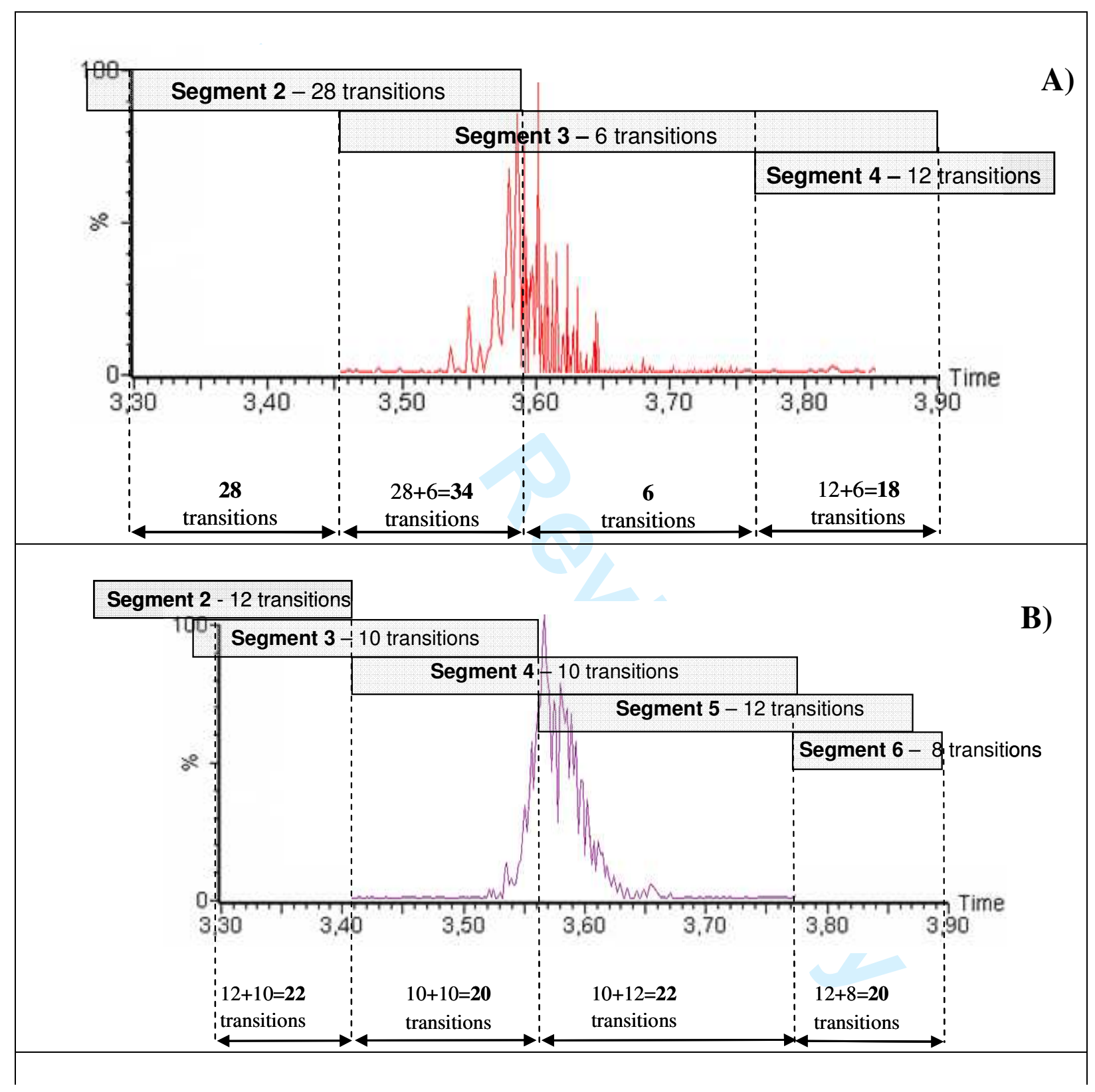




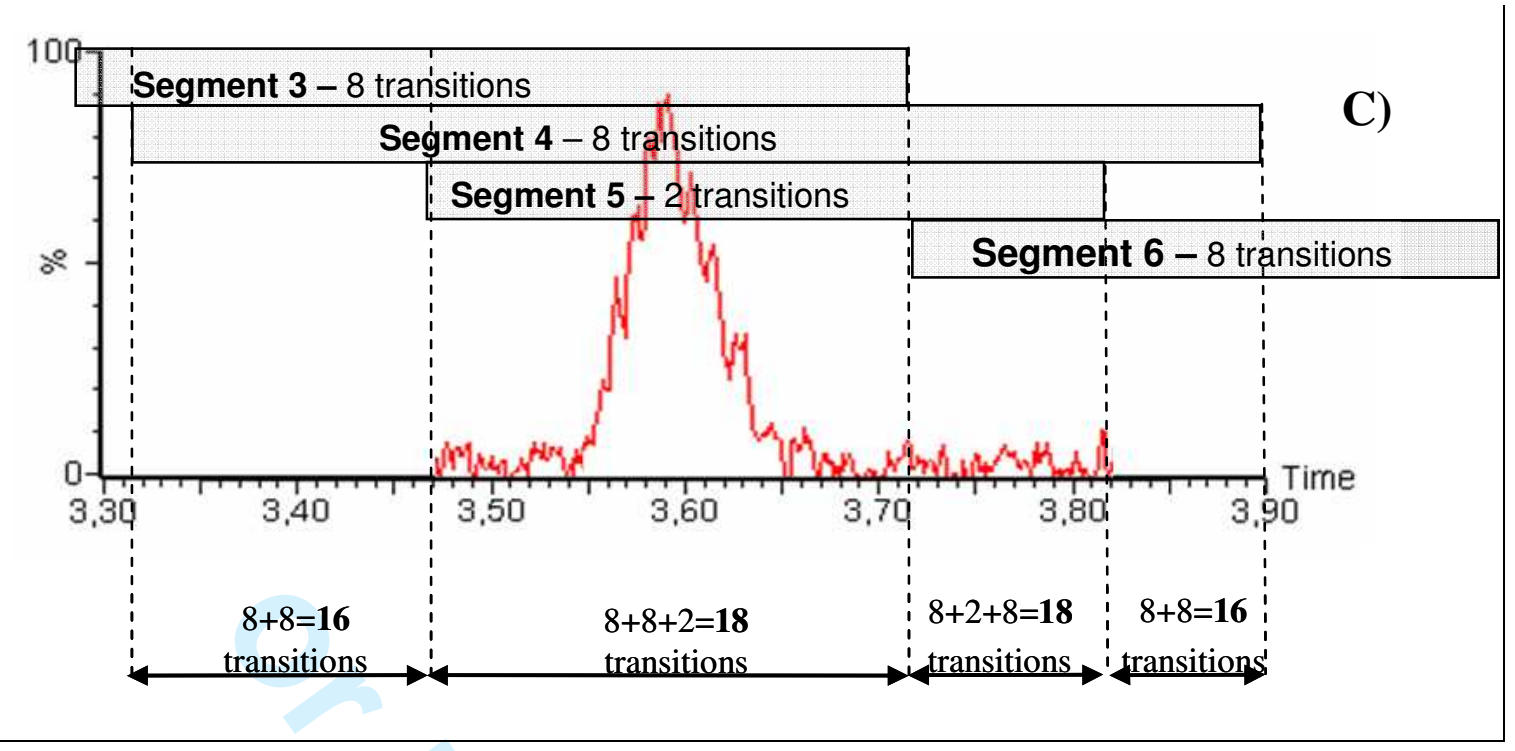


Figure 2: Calibration curves.

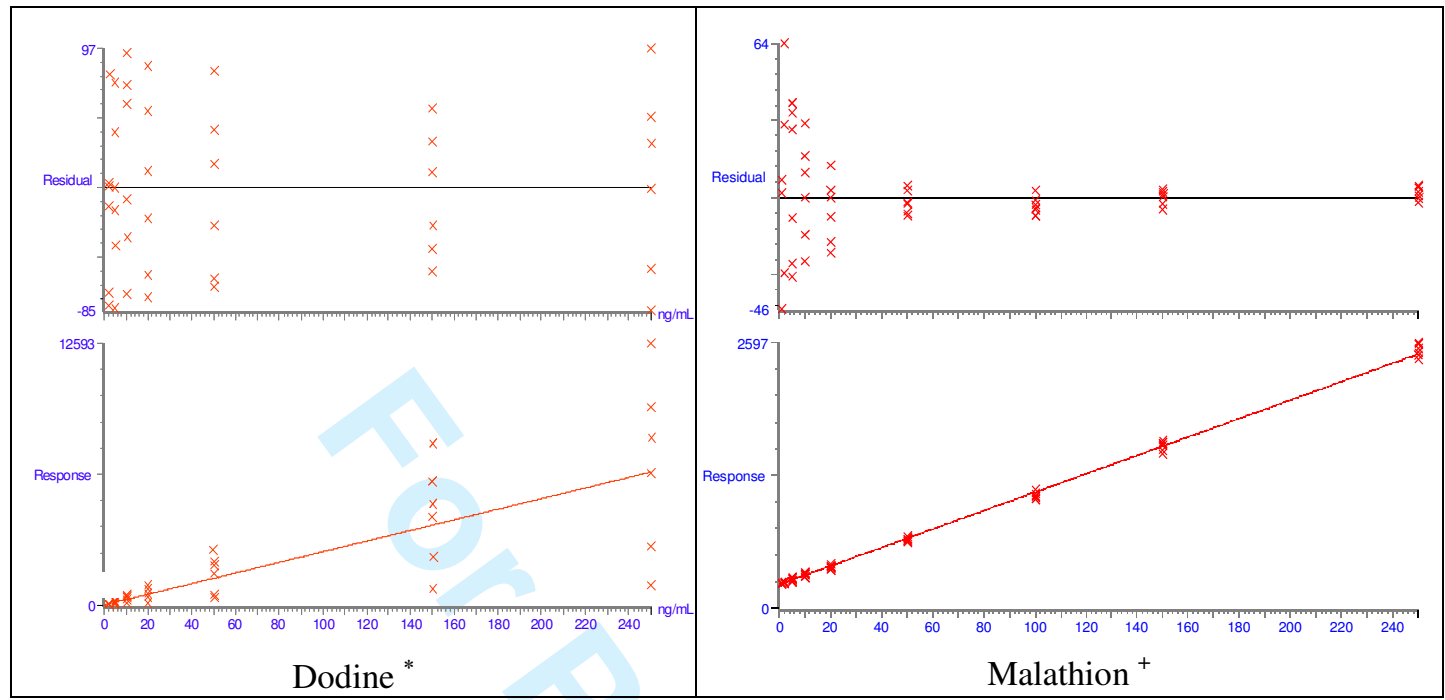

Rather poor repeatability of dodine over the whole calibration range is compared with calibration curve of malathion. In case of malathion as well as most pesticides calibration curves were linear $\left(\mathrm{R}^{2}>0.98\right)$. Spiked apple extracts were used for calibration within one sequence containing six calibration sets (each had 10 points ranging from $0.25-250 \mu \mathrm{g} \mathrm{kg}^{-1}$ ).

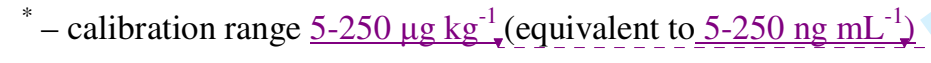

${ }^{+}$- calibration range $1-250 \mu \mathrm{g} \mathrm{kg}^{-1}$ (equivalent to $1-250 \mathrm{ng} \mathrm{mL}^{-1}$ )
}

Deleted: $5-250 \mathrm{ng} \mathrm{mL}^{-1}$

Deleted: 5-250 $\left.\mu \mathrm{g} \mathrm{kg}^{-1}\right)$. Within one sequence six calibration sets (each had 10 points ranging from $0.25-250 \mathrm{ng} \mathrm{mL}^{-1}$ ).

Deleted: $\mathrm{ng} \mathrm{mL}^{-1}$

Deleted: $\mu \mathrm{g} \mathrm{kg}^{-1}$

Deleted: . 
Figure 3: Combined UPLC-MS/MS MRM chromatogram based on the quantifying MS/MS transitions (Table 1) of spiked apple extracts at $0.05 \mathrm{mg} \mathrm{kg}^{-1}$.

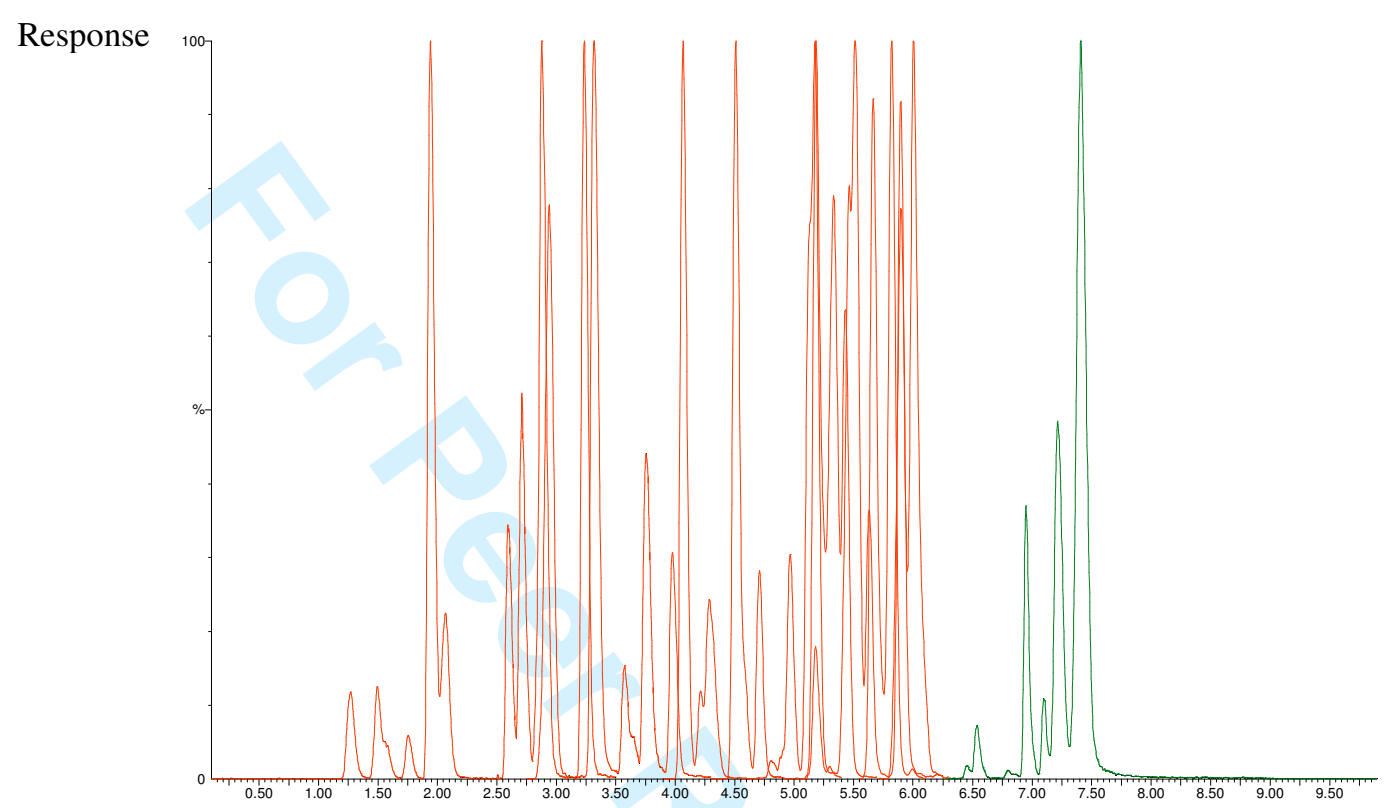


Figure 4: Comparison of different LC-MS/MS methods

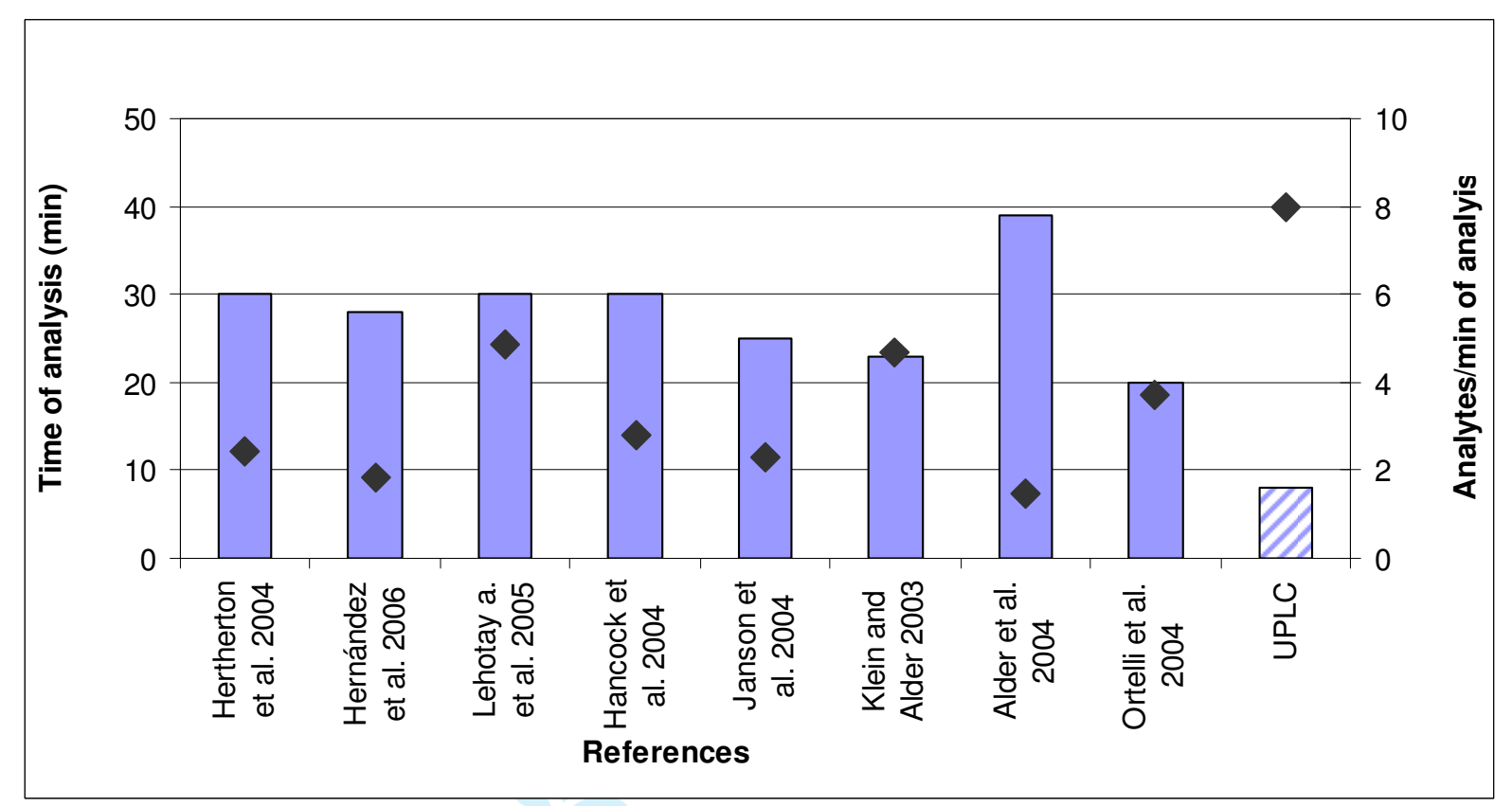


Table 1: Selected chromatographic and MS/MS (in ESI, positive mode) parameters for analysis of 64 target pesticides

\begin{tabular}{|c|c|c|c|c|c|c|c|c|c|}
\hline & Pesticide & $\mathrm{RT}(\min )$ & $\begin{array}{c}\text { RSD RT } \\
(\%)\end{array}$ & MS/M & $\begin{array}{l}\text { IS tra } \\
(\mathrm{m} / \mathrm{z}\end{array}$ & nsitions & $\begin{array}{c}\text { Cone voltage } \\
\text { (V) }\end{array}$ & $\begin{array}{c}\text { Collison energy } \\
(\mathrm{eV})\end{array}$ & $\begin{array}{l}\text { MRM } \\
\text { segment }\end{array}$ \\
\hline \multirow[t]{2}{*}{1} & Methamidophos & 1.27 & 0.34 & 142 & $>$ & 94 & 40 & 13 & \\
\hline & & & & 142 & $>$ & 125 & 40 & 13 & \\
\hline \multirow[t]{2}{*}{2} & Omethoate & 1.50 & 0.27 & 214 & $>$ & 183 & 20 & 22 & \\
\hline & & & & 214 & $>$ & 125 & 20 & 11 & \\
\hline \multirow[t]{2}{*}{3} & Aldicarb sulfoxide & 1.59 & 0.31 & 224 & $>$ & 150 & 22 & 16 & \\
\hline & & & & 224 & $>$ & 187 & 22 & 8 & \\
\hline \multirow[t]{2}{*}{4} & Aldicarb sulfone & 1.76 & 0.35 & 240 & $>$ & 223 & 33 & 8 & \\
\hline & & & & 240 & $>$ & 148 & 33 & 13 & \\
\hline \multirow[t]{2}{*}{5} & Oxydemeton methyl & 1.94 & 0.28 & 247 & $>$ & 169 & 35 & 15 & \\
\hline & & & & 247 & $>$ & 105 & 35 & 15 & \\
\hline \multirow[t]{2}{*}{6} & Methomyl & 2.05 & 0.35 & 163 & $>$ & 88 & 20 & 10 & \\
\hline & & & & 163 & $>$ & 106 & 20 & 10 & \\
\hline \multirow[t]{2}{*}{7} & Demeton-S-methyl sulfone & 2.08 & 0.27 & 263 & $>$ & 169 & 40 & 20 & \\
\hline & & & & 263 & $>$ & 109 & 40 & 20 & \\
\hline \multirow[t]{2}{*}{8} & Imidacloprid & 2.60 & 0.30 & 256 & $>$ & 209 & 29 & 16 & \\
\hline & & & & 256 & $>$ & 175 & 29 & 15 & \\
\hline \multirow[t]{2}{*}{9} & Methiocarb sulfoxide & 2.71 & 0.29 & 242 & $>$ & 185 & 39 & 13 & \\
\hline & & & & 242 & $>$ & 170 & 30 & 14 & \\
\hline \multirow[t]{2}{*}{10} & Methiocarb sulfone & 2.86 & 0.24 & 218 & $>$ & 122 & 29 & 15 & \\
\hline & & & & 218 & $>$ & 201 & 29 & 15 & \\
\hline \multirow[t]{2}{*}{11} & Carbofuran 3-hydroxy & 2.89 & 0.27 & 238 & $>$ & 163 & 29 & 14 & \\
\hline & & & & 238 & $>$ & 181 & 29 & 14 & \\
\hline \multirow[t]{2}{*}{12} & Bentazone & 2.88 & 0.34 & 238 & $>$ & 135 & 40 & 25 & \\
\hline & & & & 238 & $>$ & 137 & 40 & 25 & \\
\hline \multirow[t]{2}{*}{13} & Acetamiprid & 2.92 & 0.29 & 223 & $>$ & 126 & 31 & 14 & \\
\hline & & & & 223 & $>$ & 56 & 31 & 14 & , \\
\hline \multirow[t]{2}{*}{14} & Dimethoate & 2.95 & 0.18 & 230 & $>$ & 125 & 30 & 30 & \\
\hline & & & & 230 & $>$ & 79 & 30 & 30 & \\
\hline \multirow[t]{2}{*}{15} & Thiacloprid & 3.24 & 0.20 & 253 & $>$ & 126 & 35 & 25 & \\
\hline & & & & 253 & $>$ & 186 & 35 & 14 & \\
\hline
\end{tabular}


1

Table 1 (continued)

\begin{tabular}{|c|c|c|c|c|c|c|c|c|c|}
\hline \multirow[t]{2}{*}{16} & Carbendazim & 3.32 & 0.11 & 192 & $>$ & 160 & 35 & 22 & \multirow{2}{*}{4} \\
\hline & & & & 192 & $>$ & 132 & 35 & 22 & \\
\hline \multirow[t]{2}{*}{17} & Aldicarb & 3.61 & 0.13 & 116 & $>$ & 89 & 43 & 8 & \multirow{2}{*}{5} \\
\hline & & & & 116 & $>$ & 70 & 43 & 8 & \\
\hline \multirow[t]{2}{*}{18} & Dichlofluanid & 3.66 & 0.27 & 201 & $>$ & 92 & 40 & 30 & \\
\hline & & & & 201 & $>$ & 137 & 40 & 30 & \\
\hline \multirow[t]{2}{*}{19} & Thiabendazole & 3.76 & 0.15 & 202 & $>$ & 175 & 40 & 25 & \\
\hline & & & & 202 & $>$ & 131 & 40 & 25 & \\
\hline \multirow[t]{2}{*}{20} & Thiophanate-methyl & 3.98 & 0.14 & 343 & $>$ & 151 & 41 & 19 & \\
\hline & & & & 192 & $>$ & 160 & 41 & 17 & \\
\hline \multirow[t]{2}{*}{21} & Carbofuran & 4.07 & 0.10 & 222 & $>$ & 165 & 26 & 12 & \\
\hline & & & & 222 & $>$ & 123 & 26 & 22 & \\
\hline \multirow[t]{2}{*}{22} & Malaoxon & 4.17 & 0.09 & 315 & $>$ & 127 & 30 & 30 & \\
\hline & & & & 315 & $>$ & 99 & 30 & 11 & 6 \\
\hline \multirow[t]{2}{*}{23} & Carbaryl & 4.28 & 0.21 & 202 & $>$ & 145 & 16 & 9 & \\
\hline & & & & 202 & $>$ & 127 & 16 & 27 & \\
\hline \multirow[t]{2}{*}{24} & Thiodicarb & 4.33 & 0.17 & 355 & $>$ & 88 & 30 & 10 & \\
\hline & & & & 355 & $>$ & 108 & 30 & 12 & \\
\hline \multirow[t]{2}{*}{25} & Tolylfluanid & 4.42 & 0.18 & 347 & $>$ & 238 & 40 & 15 & \\
\hline & & & & 347 & $>$ & 137 & 40 & 15 & \\
\hline \multirow[t]{2}{*}{26} & Phorate sulfoxide & 4.50 & 0.13 & 277 & $>$ & 97 & 39 & 13 & \\
\hline & & & & 277 & $>$ & 143 & 39 & 27 & \\
\hline \multirow[t]{2}{*}{27} & Pirimicarb & 4.51 & 0.10 & 239 & $>$ & 72 & 30 & 20 & \\
\hline & & & & 239 & $>$ & 182 & 30 & 18 & \\
\hline \multirow[t]{2}{*}{28} & Phorate sulfon & 4.58 & 0.21 & 293 & $>$ & 97 & 37 & 30 & \\
\hline & & & & 293 & $>$ & 115 & 37 & 35 & \\
\hline \multirow[t]{2}{*}{29} & Metalaxyl & 4.71 & 0.12 & 280 & $>$ & 220 & 23 & 13 & \\
\hline & & & & 280 & $>$ & 248 & 23 & 10 & \\
\hline \multirow[t]{2}{*}{30} & Phorate oxon & 4.86 & 0.22 & 245 & $>$ & 75 & 30 & 12 & \\
\hline & & & & 245 & $>$ & 48 & 30 & 25 & \\
\hline \multirow[t]{2}{*}{31} & Triforine & 4.81 & 0.23 & 390 & $>$ & 98 & 46 & 28 & \\
\hline & & & & 390 & $>$ & 215 & 46 & 28 & \\
\hline \multirow[t]{2}{*}{32} & Azoxystrobin & 4.97 & 0.17 & 404 & $>$ & 344 & 25 & 10 & \multirow{2}{*}{8} \\
\hline & & & & 404 & $>$ & 329 & 25 & 10 & \\
\hline
\end{tabular}


Table 1 (continued)

\begin{tabular}{|c|c|c|c|c|c|c|c|c|c|}
\hline \multirow[t]{2}{*}{33} & \multirow[t]{2}{*}{ Linuron } & \multirow[t]{2}{*}{5.13} & \multirow[t]{2}{*}{0.16} & \multirow{2}{*}{$\begin{array}{l}249 \\
249\end{array}$} & \multirow{2}{*}{$\begin{array}{l}> \\
>\end{array}$} & \multirow{2}{*}{$\begin{array}{c}\mathbf{1 6 0} \\
182\end{array}$} & \multirow{2}{*}{$\begin{array}{l}33 \\
33\end{array}$} & \multirow{2}{*}{$\begin{array}{l}17 \\
17\end{array}$} & \multirow{2}{*}{8} \\
\hline & & & & & & & & & \\
\hline \multirow[t]{2}{*}{34} & Pyrimethanil & 5.18 & 0.09 & 200 & $>$ & 82 & 54 & 24 & \\
\hline & & & & 200 & $>$ & 107 & 54 & 24 & \\
\hline \multirow[t]{2}{*}{35} & Azinphos-methyl & 4.88 & 0.30 & 318 & $>$ & 160 & 25 & 10 & \\
\hline & & & & 318 & $>$ & 132 & 25 & 10 & \\
\hline \multirow[t]{2}{*}{36} & Methiocarb & 5.18 & 0.08 & 226 & $>$ & 169 & 26 & 9 & \\
\hline & & & & 226 & $>$ & 121 & 26 & 20 & \\
\hline \multirow[t]{2}{*}{37} & Malathion & 5.25 & 0.36 & 331 & $>$ & 99 & 50 & 30 & \\
\hline & & & & 331 & $>$ & 125 & 50 & 33 & \\
\hline \multirow[t]{2}{*}{38} & Triadimefon & 5.32 & 0.13 & 294 & $>$ & 69 & 40 & 15 & \\
\hline & & & & 294 & $>$ & 197 & 40 & 18 & \\
\hline \multirow[t]{2}{*}{39} & Myclobutanil & 5.36 & 0.15 & 289 & $>$ & 70 & 26 & 25 & \\
\hline & & & & 289 & $>$ & 125 & 25 & 13 & 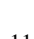 \\
\hline \multirow[t]{2}{*}{40} & Fenhexamid & 5.44 & 0.13 & 302 & $>$ & 97 & 40 & 30 & \\
\hline & & & & 302 & $>$ & 55 & 40 & 20 & \\
\hline \multirow[t]{2}{*}{41} & Diphenylamine & 5.48 & 0.17 & 170 & $>$ & 93 & 36 & 20 & \\
\hline & & & & 170 & $>$ & 92 & 36 & 20 & \\
\hline \multirow[t]{2}{*}{42} & Epoxiconazole & 5.53 & 0.12 & 330 & $>$ & 121 & 30 & 19 & \\
\hline & & & & 330 & $>$ & 141 & 30 & 19 & \\
\hline \multirow[t]{2}{*}{43} & Flusilazole & 5.63 & 0.14 & 316 & $>$ & 247 & 25 & 19 & \\
\hline & & & & 316 & $>$ & 165 & 25 & 19 & \\
\hline \multirow[t]{2}{*}{44} & Bentazone-8-hydroxy & 5.87 & 0.16 & 300 & $>$ & 258 & 35 & 20 & 12 \\
\hline & & & & 300 & $>$ & 179 & 35 & 20 & \\
\hline \multirow[t]{2}{*}{45} & Cyprodinil & 5.90 & 0.11 & 226 & $>$ & 93 & 40 & 35 & \\
\hline & & & & 226 & $>$ & 77 & 40 & 28 & \\
\hline \multirow[t]{2}{*}{46} & Triadimenol & 5.45 & 0.18 & 294 & $>$ & 69 & 40 & 15 & \\
\hline & & & & 294 & $>$ & 197 & 35 & 18 & \\
\hline \multirow[t]{2}{*}{47} & Diflubenzuron & 5.66 & 0.19 & 311 & $>$ & 158 & 25 & 10 & \\
\hline & & & & 311 & $>$ & 141 & 25 & 29 & \\
\hline \multirow[t]{2}{*}{48} & Bupirimate & 5.67 & 0.21 & 317 & $>$ & 166 & 35 & 25 & \\
\hline & & & & 317 & $>$ & 108 & 35 & 25 & \\
\hline
\end{tabular}


Table 1 (continued)

\begin{tabular}{|c|c|c|c|c|c|c|c|c|c|}
\hline 49 & Kresoxim methyl & 5.75 & 0.19 & 314 & $>$ & 222 & 30 & 9 & \multirow{4}{*}{13} \\
\hline \multirow{3}{*}{50} & & & & 314 & $>$ & 267 & 30 & 14 & \\
\hline & \multirow[t]{2}{*}{ Penconazole } & 5.83 & 0.11 & 284 & $>$ & 159 & 35 & 30 & \\
\hline & & & & 284 & $>$ & 70 & 35 & 32 & \\
\hline \multirow[t]{2}{*}{51} & Tebuconazole & 5.83 & 0.16 & 308 & $>$ & 70 & 34 & 14 & \\
\hline & & & & 308 & $>$ & 125 & 34 & 30 & \\
\hline \multirow[t]{2}{*}{52} & Imazalil & 5.86 & 0.14 & 297 & $>$ & 255 & 35 & 20 & \\
\hline & & & & 297 & $>$ & 201 & 35 & 20 & \\
\hline \multirow[t]{2}{*}{53} & Propiconazole & 5.90 & 0.23 & 342 & $>$ & 159 & 43 & 25 & \\
\hline & & & & 342 & $>$ & 69 & 43 & 20 & \\
\hline \multirow[t]{2}{*}{54} & Triflumuron & 5.91 & 0.10 & 357 & $>$ & 154 & 29 & 11 & \\
\hline & & & & 357 & $>$ & 177 & 29 & 11 & \\
\hline \multirow[t]{2}{*}{55} & Bitertanol & 5.98 & 0.33 & 338 & $>$ & 269 & 20 & 9 & \\
\hline & & & & 338 & $>$ & 99 & 20 & 14 & \\
\hline \multirow[t]{2}{*}{56} & Prochloraz & 6.00 & 0.08 & 376 & $>$ & 308 & 24 & 11 & \\
\hline & & & & 378 & $>$ & 310 & 24 & 11 & \\
\hline \multirow[t]{2}{*}{57} & Phorate & 6.02 & 0.12 & 261 & $>$ & 75 & 40 & 11 & \\
\hline & & & & $\mathrm{x}$ & & $\mathrm{x}$ & $\mathrm{x}$ & $\mathrm{X}$ & \\
\hline \multirow[t]{2}{*}{58} & Difenoconazole & 6.08 & 0.26 & 406 & & 251 & 50 & 20 & \\
\hline & & & & 406 & $>$ & 337 & 50 & 20 & \\
\hline \multirow[t]{2}{*}{59} & Dodine & 6.43 & 0.69 & 228 & $>$ & 57 & 45 & 22 & \\
\hline & & & & 228 & $>$ & 186 & 45 & 18 & \\
\hline \multirow[t]{2}{*}{60} & Teflubenzuron & 6.46 & 0.13 & 381 & $>$ & 158 & 23 & 13 & \\
\hline & & & & 381 & $>$ & 141 & 23 & 13 & \\
\hline \multirow[t]{2}{*}{61} & Flufenoxuron & 6.54 & 0.10 & 487 & $>$ & 467 & 35 & 11 & \\
\hline & & & & 489 & $>$ & 469 & 35 & 11 & \\
\hline \multirow[t]{2}{*}{62} & Fenazaquin & 6.95 & 0.16 & 307 & $>$ & $\mathbf{5 3}$ & 21 & 24 & \\
\hline & & & & 307 & $>$ & 161 & 21 & 16 & \\
\hline \multirow[t]{2}{*}{63} & Etofenprox & 7.10 & 0.32 & 394 & $>$ & 177 & 20 & 14 & \\
\hline & & & & 394 & $>$ & 135 & 20 & 26 & \\
\hline \multirow[t]{2}{*}{64} & Spiroxamin & 7.41 & 0.13 & 298 & $>$ & 101 & 40 & 25 & \\
\hline & & & & 298 & $>$ & 144 & 40 & 25 & \\
\hline
\end{tabular}

$\overline{\text { Quantitation MS/MS transitions are highlited by bold }}$

$\mathrm{x}$ - second transition was not established 
Table 2: Sequence used for estimation of matrix effect values

\begin{tabular}{|l|cccc|cccc|cccc|}
\hline Injection order & 1 & 2 & 3 & 4 & 5 & 6 & 7 & 8 & 9 & 10 & 11 & 12 \\
\hline Sample code & $\mathrm{S}_{3}$ & $\mathrm{M}_{3}$ & $\mathrm{~S}_{3}$ & $\mathrm{~B}$ & $\mathrm{~S}_{2}$ & $\mathrm{M}_{2}$ & $\mathrm{~S}_{2}$ & $\mathrm{~B}$ & $\mathrm{~S}_{1}$ & $\mathrm{M}_{1}$ & $\mathrm{~S}_{1}$ & $\mathrm{~B}$ \\
\hline Concentration levels $\left(\mathrm{ng} \mathrm{mL}_{-}^{-1}\right)$ & & 50 & & - & & 20 & & - & & 10 & & - \\
\hline
\end{tabular}

Deleted: $\mu \mathrm{g}$

For apple extracts (sample $\mathrm{B}$ and $\mathrm{M}$ ) the concentration correspond to $\mu \mathrm{g} \mathrm{kg}^{-1}$ in the sample

M1-M3 - spiked purified apple extracts; S1-S3 - standards in pure solvent; B - blank apple

extracts. For more details see Experimental. 


\section{Table 3}

Performance characteristics obtained by repeated UPLC-MS/MS analyses $(n=6)$ of spiked apple extracts (concentrations of target analytes corresponded to contamination level $\left.10 \mu \mathrm{g} \mathrm{kg}^{-1}\right)$

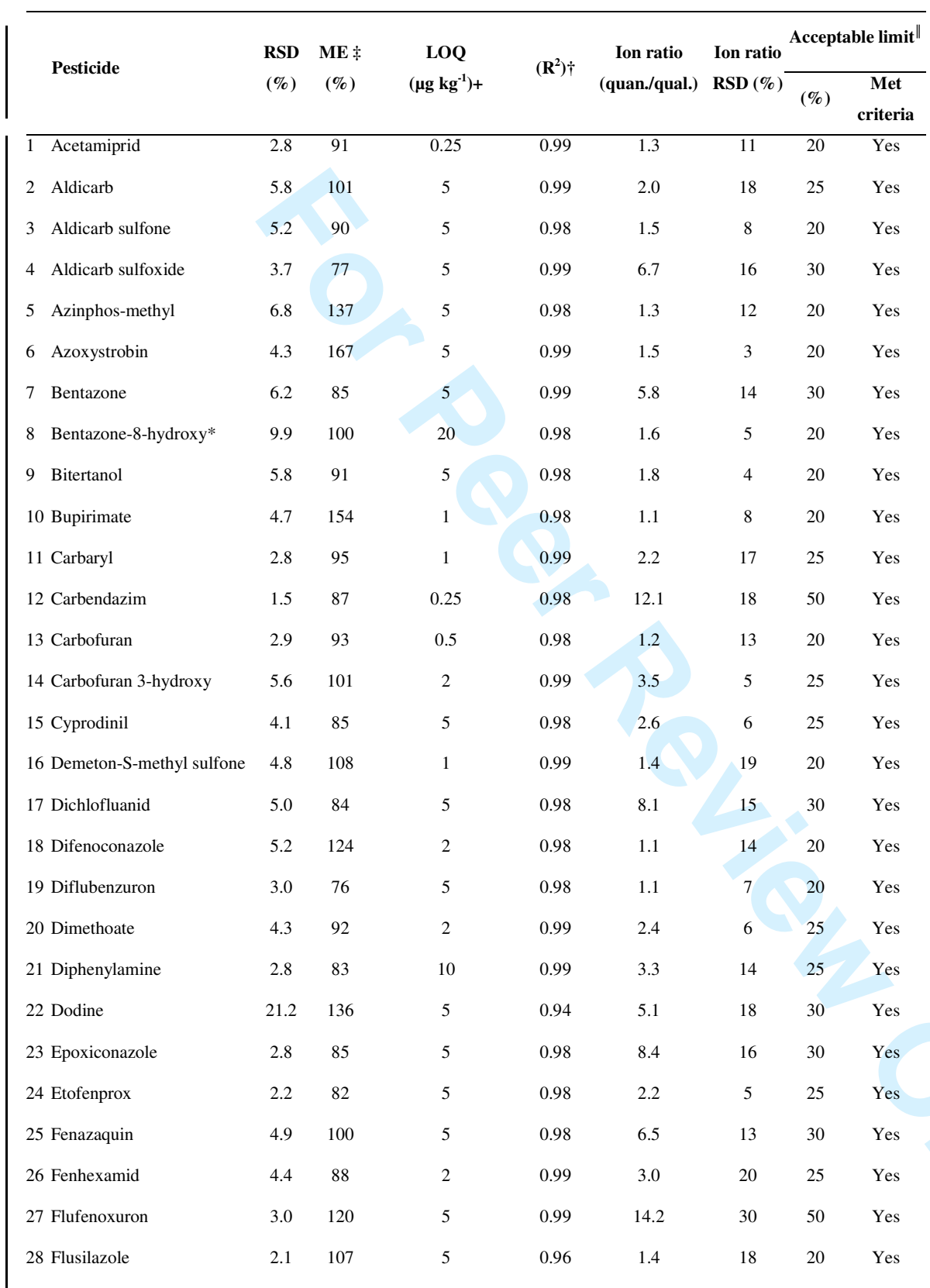


Table 3 (continued)

\begin{tabular}{|c|c|c|c|c|c|c|c|c|}
\hline \multirow{2}{*}{ Pesticide } & \multirow{2}{*}{$\begin{array}{l}\text { RSD } \\
(\%)\end{array}$} & \multirow{2}{*}{$\begin{array}{l}\text { ME } \\
(\%)\end{array}$} & \multirow{2}{*}{$\begin{array}{c}\text { LOQ } \\
\left(\mu \mathrm{g} \mathrm{kg}^{-1}\right)+\end{array}$} & \multirow{2}{*}{$\left(\mathbf{R}^{2}\right) \dagger$} & \multirow{2}{*}{$\begin{array}{c}\text { Ion ratio } \\
\text { (quan./qual.) }\end{array}$} & \multirow{2}{*}{$\begin{array}{l}\text { Ion ratio } \\
\text { RSD (\%) }\end{array}$} & \multicolumn{2}{|c|}{ Acceptable limit $\|$} \\
\hline & & & & & & & $(\%)$ & $\begin{array}{c}\text { Met } \\
\text { criteria }\end{array}$ \\
\hline 29 Imazalil & 3.4 & 79 & 5 & 0.99 & 1.4 & 10 & 20 & Yes \\
\hline 30 Imidacloprid & 3.7 & 83 & 2 & 0.99 & 1.5 & 5 & 20 & Yes \\
\hline 31 Kresoxim methyl & 9.7 & 90 & 5 & 0.98 & 1.2 & 15 & 20 & Yes \\
\hline 32 Linuron & 4.3 & 85 & 1 & 0.98 & 1.8 & 3 & 20 & Yes \\
\hline 33 Malaoxon & 4.5 & 116 & 1 & 0.99 & 4.4 & 14 & 25 & Yes \\
\hline 34 Malathion & 5.5 & 106 & 1 & 0.98 & 3.2 & 12 & 25 & Yes \\
\hline 35 Metalaxyl & 5.9 & 95 & 1 & 0.98 & 2.3 & 8 & 25 & Yes \\
\hline 36 Methamidophos & 4.4 & 80 & 2 & 0.99 & 2.5 & 19 & 25 & Yes \\
\hline 37 Methiocarb & 3.4 & 119 & 1 & 0.99 & 1.5 & 14 & 20 & Yes \\
\hline 38 Methiocarb sulfone & 8.7 & 92 & 5 & 0.99 & 179 & 28 & 50 & Yes \\
\hline 39 Methiocarb sulfoxide & 9.2 & 148 & 5 & 0.98 & 2.8 & 19 & 25 & Yes \\
\hline 40 Methomyl & 5.5 & 77 & 1 & 0.99 & 1.1 & 17 & 20 & Yes \\
\hline 41 Myclobutanil & 2.2 & 100 & 1 & 0.99 & 2.8 & 20 & 25 & Yes \\
\hline 42 Omethoate & 3.8 & 96 & 1 & 0.99 & 6.5 & 15 & 30 & Yes \\
\hline 43 Oxydemeton methyl & 4.6 & 97 & 1 & 0.99 & 3.3 & 4 & 25 & Yes \\
\hline 44 Penconazole & 4.6 & 85 & 2 & 0.99 & 1.3 & 10 & 20 & Yes \\
\hline 45 Phorate & 6.1 & 92 & 5 & 0.98 & $\mathrm{x}$ & & $\mathrm{x}$ & No \\
\hline 46 Phorate oxon* & 4.5 & 103 & 20 & 0.98 & 33.8 & 20 & 50 & Yes \\
\hline 47 Phorate sulfon & 9.9 & 92 & 1 & 0.99 & 1.9 & 12 & 20 & Yes \\
\hline 48 Phorate sulfoxide & 7.8 & 93 & 1 & 0.99 & 1.2 & 15 & 20 & Yes \\
\hline 49 Pirimicarb & 4.0 & 86 & 0.5 & 0.99 & 3.7 & 17 & 25 & Yes \\
\hline 50 Prochloraz & 2.8 & 85 & 5 & 0.98 & 4.6 & 5 & 20 & Yes \\
\hline 51 Propiconazole & 3.6 & 93 & 5 & 0.98 & 1.4 & 14 & 20 & Yes \\
\hline 52 Pyrimethanil & 5.3 & 100 & 2 & 0.99 & 1.1 & 13 & 20 & Yes \\
\hline 53 Spiroxamin & 9.2 & 55 & 2 & 0.98 & 2.5 & 5 & 25 & Yes \\
\hline 54 Tebuconazole & 4.1 & 95 & 2 & 0.98 & 5.6 & 22 & 30 & Yes \\
\hline 55 Teflubenzuron & 6.8 & 87 & 5 & 0.98 & 6.6 & 12 & 30 & Yes \\
\hline 56 Thiabendazole & 3.3 & 78 & 1 & 0.99 & 6.6 & 5 & 20 & Yes \\
\hline 57 Thiacloprid & 4.2 & 94 & 0.5 & 0.99 & 1.4 & 16 & 50 & Yes \\
\hline
\end{tabular}




\begin{tabular}{|c|c|c|c|c|c|c|c|c|}
\hline \multirow[b]{2}{*}{ Pesticide } & \multirow{2}{*}{$\begin{array}{l}\text { RSD } \\
(\%)\end{array}$} & \multirow{2}{*}{$\begin{array}{l}\text { ME } \\
(\%)\end{array}$} & \multirow{2}{*}{$\begin{array}{c}\text { LOQ } \\
\left(\mu \mathrm{kg}^{-1}\right)+\end{array}$} & \multirow[b]{2}{*}{$\mathbf{R}^{2} \dagger$} & \multirow{2}{*}{$\begin{array}{c}\text { Ion ratio } \\
\text { (quan./qual.) }\end{array}$} & \multirow{2}{*}{$\begin{array}{l}\text { Ion ratio } \\
\text { RSD (\%) }\end{array}$} & \multicolumn{2}{|c|}{ Acceptable limit } \\
\hline & & & & & & & $(\%)$ & $\begin{array}{c}\text { Met } \\
\text { criteria }\end{array}$ \\
\hline 58 Thiodicarb & 6.4 & 129 & 2 & 0.99 & 3.2 & 18 & 25 & Yes \\
\hline 59 Thiophanate-methyl & 6.8 & 104 & 1 & 0.99 & 9.6 & 19 & 30 & Yes \\
\hline 60 Tolylfluanid & 12.5 & 102 & 2 & 0.71 & 1.2 & 11 & 20 & Yes \\
\hline 61 Triadimefon & 6.0 & 78 & 2 & 0.99 & 1.6 & 8 & 20 & Yes \\
\hline 62 Triadimenol & 5.4 & 108 & 2 & 0.99 & 8.7 & 4 & 30 & Yes \\
\hline 63 Triflumuron & 4.9 & 86 & 5 & 0.99 & 1.9 & 6 & 20 & Yes \\
\hline 64 Triforine* & 9.5 & 96 & 20 & 0.98 & 18.1 & 33 & 50 & Yes \\
\hline
\end{tabular}

\footnotetext{
* - repeatability was calculated on LOQ

$\ddagger$ - Matrix effect calculated as described in 3.4.

$\S$ - Correlation coefficient calculated for calibration range LOQ- $250 \mu \mathrm{g} \mathrm{kg}^{-1}$

$\mathrm{x}$ - Qualifying MS/MS transitions was not established

$+-\mu \mathrm{gg}^{-1}$ correspond to $\mathrm{ng} \mathrm{mL}^{-1}$

${ }^{\|}$Specified in Commission document No. SANCO/10232/2006
} 